\title{
VÍDEOS E ANIMAÇÕES NO ENSINO DE QUÍMICA: PROBLEMATIZANDO O SURGIMENTO E EXPANSÃO DO SETOR SUCROALCOOLEIRO NA REGIÃO DE DOURADOS-MS
}

Vídeos and animations in the Chemistry education: problematizing the emergence and expansion of the sugar-alcohol sector in the region of Dourados-MS

Vídeos y animaciones en la enseñanza de Química: problematizando el surgimiento y expansión del sector sucroalcoholero en la región de Dourados-MS

Marlon Gonçalves Gauna ${ }^{1}$

Ademir de Souza Pereira²

Maria Celina Piazza Recena ${ }^{3}$

\begin{abstract}
Resumo
O artigo discute o uso de vídeos e animações, nas aulas de Química, em uma escola pública, com enfoque no surgimento das usinas sucroalcooleiras no sul de Mato Grosso do Sul e nos processos industriais para produção de açúcar e álcool. Foram selecionados e exibidos vídeos e uma animação que tratavam do tema sobre diferentes perspectivas, incluindo o impacto ambiental e social na cidade de Dourados-MS com o surgimento das plantações de cana-de-açúcar como o documentário "A sombra de um delírio verde", o processo de produção do açúcar e álcool nas usinas e o uso do etanol no cotidiano. O principal objetivo das exibições foi incentivar os alunos na formação de opinião sobre o surgimento e expansão do setor sucroalcooleiro na região e a formação de conhecimentos, sobretudo químicos em relação ao processamento da cana-deaçúcar. Considera-se que o uso dos vídeos e da animação incentivou a participação e reflexão dos alunos durante as atividades e que também estimulou o aprendizado de conceitos químicos presentes nas etapas industriais do setor sucroalcooleiro como a destilação.
\end{abstract}

PALAVRAS-CHAVE: Vídeos. Animação. Cana-de-Açúcar. Destilação.

\begin{abstract}
The article discusses the use of videos and animations in Chemistry classes at a public school, focusing on the emergence of sugarcane-alcohol companies in the south of Mato Grosso do Sul and in the industrial processes for the production of sugar and alcohol. Videos and animation were selected and displayed on different perspectives, including the environmental and social impact
\end{abstract}

\footnotetext{
1 Mestre em Ensino de Ciências/Ensino de Química, docente na escola Escola Estadual Amando de Oliveira. Endereço: Av. Manoel da Costa Lima, 1435 - Vila Piratininga, Campo Grande - MS, 79081-040. Email: marlongauna18@gmail.com

2 Mestre em Ensino de Ciências/Ensino de Química, Doutorando do Programa de Pós-graduação em Educação para a Ciência UNESP/Bauru. Docente da Universidade Federal da Grande Dourados, Faculdade de Ciências Exatas e Tecnologia, Curso de Química. Endereço: Rodovia Dourados - Itahum, Km 12 Cidade Universitária, Caixa Postal 364 -CEP 79804-970. Email: ademirpereira@ufgd.edu.br

3 Doutora em Ciências da Saúde pela Universidade de Brasília. Professora titular, aposentada e com vínculo como voluntária atuando nos mestrados de Ensino de Ciências e de Saúde da Família, bem como no doutorado em Ensino de Ciências e Educação Ambiental, da UFMS. Endereço: Av. Sen. Filinto Müler, 919, Campo Grande - MS. Email: mcrecena@yahoo.com.br
} 
in the city of Dourados-MS with the emergence of sugarcane plantations such as the documentary "A sombra de um delírio verde" , the process of production of sugar and alcohol in the mills and the use of ethanol in daily life. The main objective of the exhibitions was to encourage students to form an opinion about the emergence and expansion of the sugarcane-alcohol industry in the region and the formation of knowledge, especially chemical in relation to the processing of sugarcane. It is considered that the use of videos and animation encouraged the participation and reflection of the students during the activities and also stimulated the learning of chemical concepts present in the industrial stages of the sugarcane-alcohol sector such as distillation.

KEYWORDS: Videos. Animation. Sugarcane. Distillation.

\section{Resumen}

El artículo discute el uso de vídeos y animaciones, en las clases de Química, en una escuela pública, con enfoque en el surgimiento de las usinas sucroalcoholeras en el sur de Mato Grosso do Sul y en los procesos industriales para producción de azúcar y alcohol. Se seleccionaron y exhibieron vídeos y una animación que trataban del tema sobre diferentes perspectivas, incluyendo el impacto ambiental y social en la ciudad de Dourados-MS con el surgimiento de las plantaciones de caña de azúcar como el documental "A sombra de um delírio verde", el proceso de producción del azúcar y alcohol en las usinas y el uso del etanol en el cotidiano. El principal objetivo de las exhibiciones fue incentivar a los alumnos en la formación de opinión sobre el surgimiento y expansión del sector sucroalcoholero en la región y la formación de conocimientos, sobre todo químicos en relación al procesamiento de la caña de azúcar. Se considera que el uso de los vídeos y de la animación incentivó la participación y reflexión de los alumnos durante las actividades y que también estimuló el aprendizaje de conceptos químicos presentes en las etapas industriales del sector sucroalcoholero como la destilación.

PALABRAS ClAVE: Videos. Animación. Caña de Azúcar. Destilación.

\section{INTRODUÇÃO}

A inserção da realidade dos alunos no contexto educativo em ciências traz consigo aspectos que abordam a educação problematizadora, de forma que possa promover questionamentos e posicionamentos que proporcionem a leitura de mundo (FREIRE, 1987). Trata-se de um ensino que também é dialógico, não acontece pela transferência de saber professor-aluno, mas do diálogo de ambos, dos conhecimentos destes em relação às situações significativas, como os temas socais. A expansão do setor sucroalcooleiro influencia a região sul de Mato Grosso do Sul como tema social, pois abrange vários aspectos que podem ser problematizados, gerando posicionamentos sobre diferentes perspectivas fomentando investigações que permeiem o aprendizado dos alunos.

A problematização de conceitos nas aulas de Química pode ser feita com o auxílio de vídeos e animações, que são ferramentas que permitem diferentes processos de integração em sala, podendo ser explorados conforme os objetivos didáticos propostos.

Ferrés (1996) afirma que um bom vídeo pode servir para introduzir um novo assunto, e pode despertar a curiosidade, a motivação para novos temas, sendo apresentado, portanto, antes do conteúdo programático facilita o desejo de pesquisar nos alunos, para aprofundar o assunto do vídeo e do conteúdo escolar. O vídeo também pode simular experiências, por exemplo, de química em que são necessários reagentes de difícil acesso, ou reações que necessitam de um ambiente apropriado, e até mesmo processos 
industriais a que não se tem acesso, como a produção do açúcar e do álcool dentro das usinas.

Os vídeos podem ser classificados, segundo Arroio e Giordan (2006), em diferentes modalidades, conforme seu uso e objetivos, sendo eles vídeo-aula, vídeomotivador e vídeo-apoio. O vídeo-aula é empregado para expor algum conteúdo de forma sistematizada, exibindo informações que precisam ser ouvidas e visualizadas e que encontram no audiovisual o melhor meio de veiculação. Os autores sugerem que o vídeoaula seja utilizado como reforço da explicação prévia do professor.

A segunda modalidade, vídeo-motivador segundo os autores, além de apresentar o conteúdo ele interpela, provoca, questiona, desperta o interesse dos alunos, sendo um programa destinado para suscitar um trabalho posterior à exibição da obra. E por fim, a modalidade vídeo-apoio, são imagens em movimento que ilustram o discurso verbal do professor, permite a exposição oral dos alunos também, sendo um complemento a explicação em sala.

O vídeo também atua como um enunciador de diferentes vozes, sendo um meio de apresentar os sentidos e significados atribuídos pelos agentes sociais em relação ao tema abordado, mostrando a quem o assiste diferentes conhecimentos e perspectivas (SILVA, et. al, 2012).

Neste relato de experiência, foram empregados vídeos e na modalidade vídeomotivador, exibidos antes da explicação do conteúdo pelo professor, com objetivo de instigar os alunos para o debate, sensibilizá-los sobre como foi o surgimento das usinas de açúcar e álcool na região de Dourados-MS e os embates com os povos indígenas, bem como os impactos ambientais ocorridos. Além disso, os vídeos também foram empregados para mostrar o funcionamento de uma usina sucroalcooleira, o aproveitamento dos resíduos, a história da cana-de-açúcar no Brasil e o uso do etanol como biocombustível.

Esse recurso foi utilizado nas aulas por se considerar sua potencialidade na formação de opinião e na construção de conhecimentos por parte dos alunos, destacandose a abordagem de questões sociais e ambientais, pois:

\begin{abstract}
A linguagem do vídeo possibilita o professor deixar de ser um informador passando a ser um mediador que fomenta a autonomia do aluno. A imagem mostra-se mais eficaz que a palavra na hora de provocar emoções. Sendo assim, o vídeo desempenha um papel importante com sua capacidade de provocar emoções e sensações. A sensibilização dos alunos para os problemas ambientais é fundamental para que seja possível conscientizá-los, sensibilização essa que pode ser atingida com o auxílio do audiovisual que leva estas imagens para dentro da sala de aula (ARROIO; GIORDAN, 2006, p.7).
\end{abstract}

Além dos vídeos, o uso de animações também têm se configurado como uma possibilidade promissora no processo de ensino e aprendizagem, por ser um recurso capaz de facilitar a demonstração de processos, a visualização temporal de um dado evento, a exposição de fenômenos raros complexos ou perigosos e também para melhorar a capacidade de abstração do aluno (BIZELLI; FISCARELLI; OLIVEIRA, 2009). 
Foi utilizada durante as aulas uma animação que apresentava o processo de destilação fracionada presente nas usinas de açúcar e álcool, buscando avaliar o aprendizado dos alunos em relação a essa etapa do processo industrial da cana-de-açúcar.

O uso de animações proporciona a facilitação da construção de "modelos mentais" pelos alunos (GIORDAN, 1999) simulando fenômenos que representam a realidade, contracenando com a representação que o próprio aluno apresenta sobre o assunto abordado, estimulando-o a uma nova forma de pensar sobre o fenômeno, considerando agora, as imagens e signos presentes na animação.

\section{Aspectos metodológicos}

As atividades foram realizadas em uma escola pública da cidade de Dourados, Mato Grosso do Sul, com 35 alunos do terceiro ano do ensino médio. O relato discorre acerca do uso de vídeos e animações no ensino de conceitos químicos e conhecimentos que envolvem a instalação de usinas sucroalcooleiras na região buscando apresentar o tema sobre diferentes perspectivas, incluindo o impacto ambiental e social na cidade de Dourados-MS com o surgimento das plantações de cana-de-açúcar.

Foram utilizados três vídeos e uma animação durante a aplicação das aulas com o tema "Controvérsias do setor sucroalcooleiro". O primeiro vídeo exibido se chama "Carro inteligente filme da campanha Etanol o combustível completão" produzido pela Única (União da Indústria de cana-de-açúcar) em 2014. O vídeo de 30 segundos, com formato de comercial, promove o uso do etanol, como o "combustível do futuro", buscando incentivar mais motoristas a utilizarem-no. Os alunos foram orientados a prestarem atenção a exibição, procurando observar qual mensagem aquele vídeo queria transmitir.

O segundo vídeo exibido foi o documentário "À sombra de um delírio verde” foi lançado em 2011, e retrata o período em que as usinas de açúcar e álcool estavam se instalando no sul do estado (2005/2006), ele mostra as controvérsias dessas instalações, como isso impactou a vida de povos indígenas (guarani-kaiowa) da região, que viram suas terras reivindicadas se transformarem em grandes canaviais e membros de suas comunidades servirem de mão-de-obra barata para as usinas, vivendo em condições trabalhistas desumanas. Além disso, o documentário retrata aspectos econômicos, da causa do crescimento do setor, por conta da demanda por etanol e impactos ambientais provenientes do plantio e processamento da cana-de-açúcar. Com 29 minutos e 36 segundos de duração foi produzido em uma parceria entre Brasil, Argentina e Bélgica, sendo premiado em vários eventos.

Em uma aula posterior foi exibido o vídeo "Processo Industrial do açúcar e álcool" com aproximadamente 9 minutos, retrata os processos industriais que envolvem a produção do açúcar e álcool, desde a colheita da cana-de-açúcar na lavoura até a distribuição comercial pelas usinas.

Após os vídeos, surgiram momentos de discussão com o professor e também a resolução individual de questionários para avaliar o aprendizado do tema apresentado.

Os vídeos atuaram como vídeo-motivador, (ARROIO; GIORDAN, 2006) anterior a discussão do tema na aula, para que os alunos despertassem o interesse e avaliassem as situações apresentadas nos vídeos afim de construírem argumentos e conhecimentos para os questionários e debates posteriores.

E por fim, foi exibida uma animação sobre o processo de destilação, afim de avaliar o aprendizado dos estudantes em relação aos processos químicos presentes nas 
etapas industriais da cana-de-açúcar, os alunos foram orientados a explicarem visualizando a animação, como acontece a destilação e como ela é empregada nas usinas sucroalcooleiras.

\section{A experiência docente}

Os vídeos foram exibidos e foi notório o interesse dos alunos, já que se mantiveram em silêncio e atentos. Os alunos foram transferidos para a sala de vídeo, equipada com projetor, caixa de som, ar condicionado, cadeiras e lousa, adequada para própria exibição de vídeos. Inicialmente foram questionados se já haviam assistido o documentário "À sombra de um delírio verde", mas para minha surpresa, responderam que não tinham conhecimento da existência do vídeo.

No entanto, quando se iniciou o relato sobre o conteúdo do documentário, alguns alunos se lembraram, e comentaram que já haviam assistido em séries anteriores, nas aulas de Geografia e já conheciam a realidade que o documentário tratava. No entanto, outros alunos relataram que não conheciam o vídeo.

Antes de apresentar o documentário "À sombra de um delírio verde”, foi exibido um vídeo intitulado "Carro inteligente filme da campanha Etanol o combustível completão" produzido pela Única (União da Indústria de cana-de-açúcar), que incentiva o uso do etanol. Após o vídeo surgiu um momento de diálogo em que o professor questionou os alunos:

$P:$ O que o vídeo quis mostrar?

A: Que o etanol é um ótimo combustível, que não polui, gera empregos, é ótimo para o meio ambiente.

$P$ : Mas isso realmente é verdade?

A: Não, tipo por que plantando cana depois de cinco anos aquela terra não serve para mais nada.

O posicionamento do aluno, neste diálogo, evidencia um conhecimento prévio, de forma crítica em relação ao meio ambiente e a produção do etanol. Iniciou-se então a exibição do documentário ao qual não deu tempo de assisti-lo inteiro durante a aula, sendo interrompido para exibição na aula posterior. Após o documentário, os alunos responderam um questionário que relacionava aspectos apresentados nos dois vídeos.

Também foi exibido em outra aula o vídeo "Processo Industrial do açúcar e álcool" afim de demonstrar como acontece a produção de açúcar e álcool nas usinas sucroalcooleiras. Anteriormente, os alunos foram instigados a responderem sobre como eles pensam que ocorre a produção do açúcar e álcool, que etapas envolvem essa produção. O professor anotou no quadro várias palavras (Quadro 1) que são correspondentes às etapas que envolvem a cana-de-açúcar em uma usina de açúcar e álcool. 
Quadro 1: Palavras utilizadas na atividade para processos industriais cana-de-açúcar

\begin{tabular}{|lrrc|}
\hline Banho Químico & Destilação & Purificação & Limpeza \\
& Separação e pesagem & cana-de-açúcar na lavoura \\
Picadores & Fermentação & Armazenamento e Logística \\
\hline
\end{tabular}

Fonte: Dados do autor.

Em seguida, foi pedido aos alunos que colocassem em uma ordem de 1 a 10 o que eles acreditassem que fosse o processamento da cana-de-açúcar, em qual das palavras se iniciava e qual terminaria, seria a última, buscando verificar o que eles sabem do processamento industrial.

Nessa etapa surgiram alguns questionamentos dos estudantes:

"O que são picadores? ”, "Armazenagem e Logística é para o etanol ou para
a cana-de-aćcar? ", "Destilar é separar? ", "Como é esse banho químico?
”e "As melhores canas vão para produção do açúcar e as piores para o
álcool?"

Alguns alunos expuseram sua forma de pensar aos colegas que estavam próximos no momento da aplicação, como as falas a seguir, em que eles procuram explicar como acontecem as etapas que envolvem a cana-de-açúcar industrialmente: "Eu acho que primeiro separa e faz tudo e depois que ele limpa", "Eu acho que limpa a cana primeiro ", "Eu não entendi o banho químico..."

Além disso, o professor deu destaque a etapa de destilação, processo importante na produção do etanol, ele perguntou no questionário: Como acontece a destilação?

A maioria dos alunos em suas respostas atribuiu a destilação o papel de separação do açúcar e do álcool.

"Eu acho que a etapa de separação do açúcar e do álcool é a destilação!"

Eles assistiram ao vídeo do processo industrial na usina sucroalcooleira e também foi realizado um experimento demonstrativo de destilação do caldo de cana fermentado, no laboratório da escola. $\mathrm{Na}$ aula posterior, foi apresentada com o uso do projetor multimídia, uma animação que mostrava a destilação como a realizada no experimento (Figura 1), a animação trazia de forma detalhada, em movimento a formação de gás no interior da vidraria e a separação de líquidos.

Os alunos deveriam relatar a partir de seus conhecimentos como acontecia o processo de destilação, o nome das vidrarias caso se lembrassem, e para o que a técnica é utilizada em uma usina de açúcar e álcool. Essa atividade pretendia verificar o aprendizado em relação ao experimento. Foi feita a seguinte colocação:

"Escreva sobre a destilação: Como é o processo? Para que é usado na usina?"

Novos termos surgiram na resposta sobre destilação como: ebulição, condensação, vapor, resfriar, separação da vinhaça. 
Figura 1: Animação utilizada para os alunos explicarem a destilação

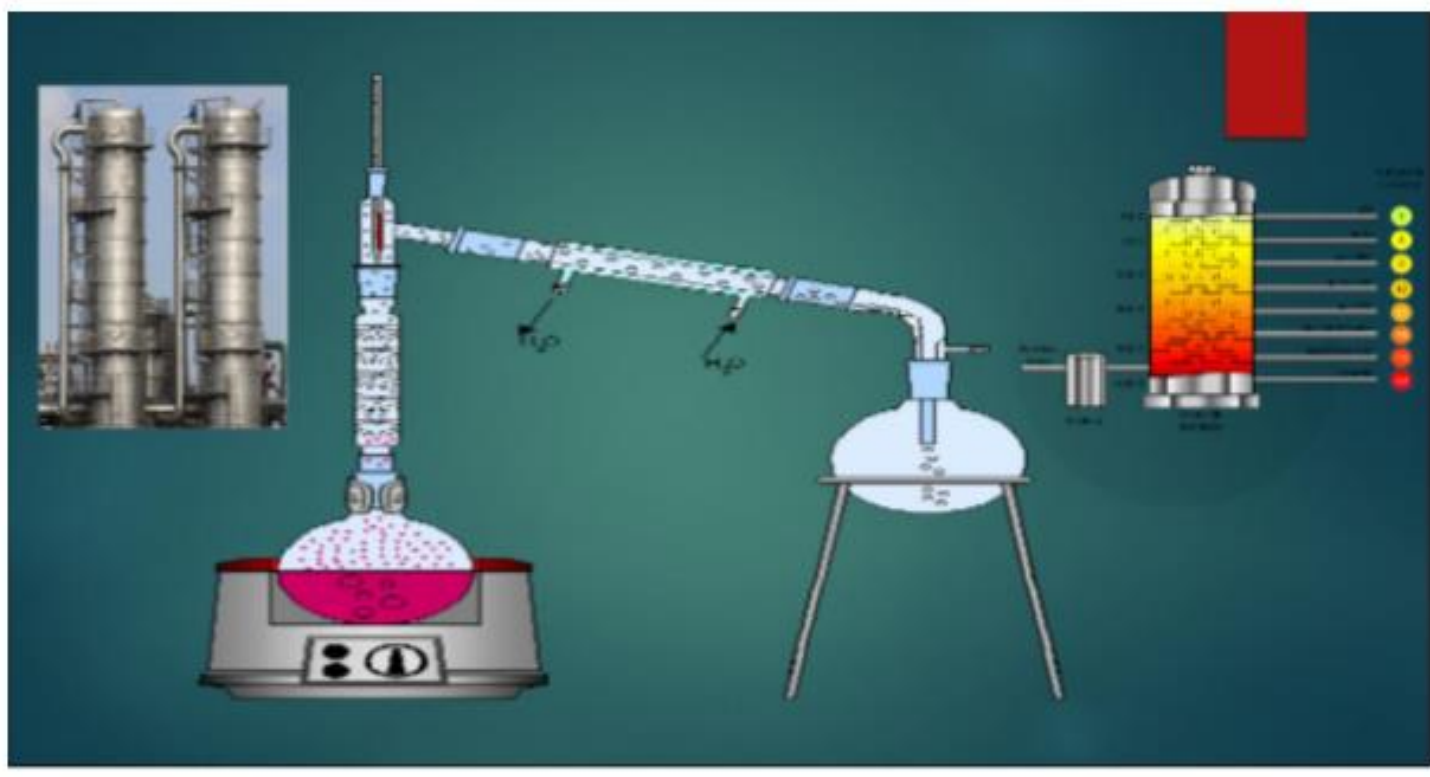

Fonte: Unesp, 2001. Site: http://www2.fc.unesp.br/lvq/animations.htm

\section{Compreensões dos alunos em relação às exibições}

Após assistirem o documentário "A sombra de um delírio verde", os alunos responderam a um questionário com cinco perguntas, destaca-se nesse relato as respostas a pergunta a seguir: verde"?

O que te chamou mais a atenção no documentário "A sombra de um delírio

O objetivo era investigar que aspectos do documentário mais impressionaram os alunos e como o documentário influenciou a percepção deles em relação ao surgimento das usinas de açúcar e álcool. Ao responderem sobre o que chamou mais atenção no documentário, os alunos foram incisivos em destacar as condições dos indígenas no início da atividade sucroalcooleira no sul do estado.

\footnotetext{
“... a exploração do trabalho manual. "

"A questão indígena pela ocupação de suas terras como as péssimas condições de trabalho, por falta de opção ao qual são submetidos" "... a luta dos índios por pedaços de terra onde a cana se encontra."

"A perda dos indigenas sobre suas terras para a plantação da cana e a falta de higiene nos dormitórios dos funcionários"

"O sofrimento dos indígenas"
}

Os alunos citaram o impasse das terras ocupadas pelos indígenas e fazem um contraponto com a exploração dessa mão-de-obra nas usinas, que o documentário retrata expondo as condições de trabalho ao qual eles eram submetidos, alguns articularam essa situação com o trabalho escravo.

"Como era feita a colheita antes da mecanização..."

"A forma precária que os trabalhadores trabalham, a forma em que os trabalhadores são vistos, como escravos, a situação das usinas"

"O trabalho escravo" 
Outro fator respondido pelos alunos que chamaram sua atenção envolve o aspecto econômico do setor:

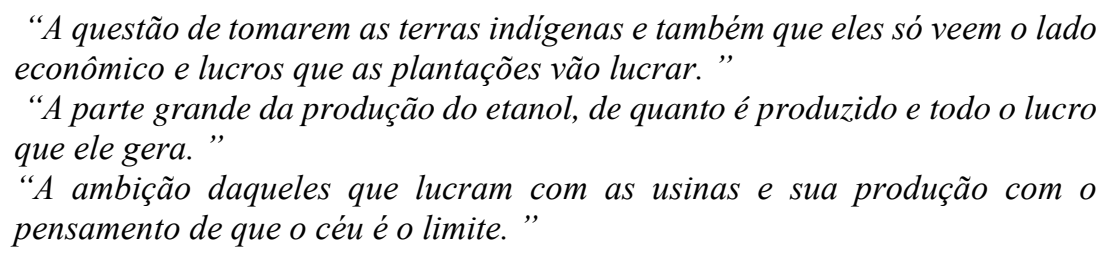

Os alunos citaram a palavra lucro, mas refletiram sobre a geração desse lucro, contextualizando com a influência na sociedade, é notório que eles não sabiam o quanto o estado produz de etanol e como isso influencia na economia, eles articularam apenas um grupo de pessoas como detentoras desse lucro ao escreverem "daqueles", "eles" e citam a ambição desse grupo ao considerarem apenas o lucro e esquecendo-se das terras indígenas, do meio ambiente, sendo uma prática capitalista sem limites.

Os vídeos demonstraram para os alunos diferentes pontos de vista sobre o mesmo tema, para que eles se posicionassem referentes ao surgimento das usinas de açúcar e álcool na região, criassem um ponto de vista crítico da realidade regional, avaliando os fatores econômicos e sociais, o que acontece atualmente e aconteceu na cidade.

Um ponto relevante no uso de vídeos no ensino é que ele permite aos alunos diferentes compreensões para o que está sendo exibido. A apreensão ao conteúdo apresentado diverge dependendo do estudante, pois o que o que é mais importante para um deles, pode ser menos importante para o outro. Nesta etapa se destaca a figura mediadora do professor no aproveitamento desse contexto para o debate, na exploração dele para a construção de conhecimentos.

Em relação aos processos industriais no setor, os alunos foram incentivados a responderem como ocorrem os processos de produção do açúcar e álcool nas usinas, citando em que momento ocorre a destilação. As respostas foram variadas, evidenciando pouco conhecimento em relação aos processos industriais.

Na pergunta sobre como acontece a destilação a maioria dos alunos respondeu que é um processo de separação:

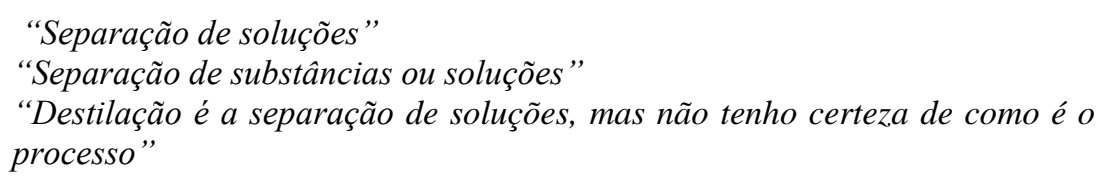

Os alunos apenas definiram em suas repostas a ideia geral do que é a destilação, mas não procuraram explicar como acontece o processo. A maioria deles atribuiu a destilação como uma etapa de separação do açúcar do álcool, demonstrando o pouco conhecimento do uso desse processo nas usinas sucroalcooleiras.

\section{"É um processo de separação do açúcar e do álcool" \\ "Com a separação do álcool do açúcar" \\ "É separado o que usa para o álcool e para o açúcar" \\ "É um processo de separação do açúcar e do álcool"}

Nota-se que por saberem previamente que existem etapas diferentes no interior das usinas para a produção dos subprodutos da cana- de-açúcar e por se lembrarem que a destilação é um processo de "separação de soluções" eles atribuíram justamente a destilação o processo de separação do açúcar e do álcool. 
Após a atividade experimental de destilação, as explicações em sala e visualizando a animação, eles passaram a apresentar uma evolução nas respostas apresentadas ao serem questionados sobre como acontece a destilação e qual a sua importância nas usinas sucroalcooleiras.

"A destilação é um processo da usina onde ocorre a separação de produtos, existe o aquecimento desses produtos, que são separados através do estado líquido e gasoso, esse processo ocorre nos destiladores ou torres de destilação de uma usina"

Percebe-se na resposta do aluno, uma transposição do processo com o que acontece nas usinas sucroalcooleiras, em que ele cita as torres de destilação.

\section{"O processo de destilação começa com o aquecimento do líquido que ao ferver libera gás. Este por sua vez sobe no balão de destilação em direção ao tubo que contém água, cuja função é resfriar para que o gás volte a ser líquido e pingar no balão volumétrico. Esse processo é usado na usina para separaro álcool da vinhaça."}

Esse aluno explica visualizando a animação, o uso do balão de destilação e ainda cita de forma correta como o processo é empregado na usina sucroalcooleira, articulando com a formação do resíduo que é produzido no setor (vinhaça).

O uso do vídeo trouxe conhecimentos químicos de processos de produção do açúcar e álcool que influenciam a economia e o meio-ambiente da cidade, proporcionando o entendimento das etapas industriais e a formação de resíduos, o vídeo estimulou os alunos pois atuou como uma visita técnica a usina sucroalcooleira, uma vez que as imagens e o áudio exibiam em detalhes todo o processo industrial da cana-de-açúcar.

\section{CONSIDERAÇÕES FINAIS}

A experiência contribuiu para entender a importância do uso de outros recursos didáticos para o ensino, percebendo o interesse, a atenção e a interação dos estudantes ao se utilizar os recursos tecnológicos.

O uso de vídeos e animações se caracterizam como recursos que apresentam potencialidades para o ensino de Química, como uma ferramenta que permite a conexão entre conceitos do conteúdo programático das aulas com a realidade do estudante, permite a contextualização usando imagens e fatos sociais.

Atualmente com várias plataformas e canais com diferentes vídeos, é interessante que o uso desse recurso com fim didático seja feito de forma planejada, acompanhada de atividades que favoreçam a reflexão do estudante em relação aos vídeos exibidos, seja por meio de um questionário posterior, ou de um debate sobre conceitos presentes no vídeo.

É fundamental que o professor assista aos vídeos anteriormente e que crie, reflita sobre que aspectos, que pontos marcantes nos vídeos serão discutidos posteriormente, buscando elementos inovadores para a aula, que despertem a curiosidade nos alunos e promovam conexões do conteúdo programático escolar com sua aplicação no cotidiano.

Dessa forma, o uso de vídeos e animações não culminam em uma mera exibição, mas serão recursos de estímulo aos estudantes para o debate e aprendizagem de conceitos que ainda serão desenvolvidos nas aulas.

É importante também, o teste dos equipamentos antes da aula, a checagem do formato do vídeo, testes do áudio, da qualidade da imagem. O recurso precisa ser 
empregado de forma planejada, do contrário os alunos podem se dispersar durante a exibição, por não conseguirem assistir de forma adequada.

Na experiência docente descrita, se destaca também o aprendizado dos alunos de como um processo de separação de misturas que é a destilação, desenvolvida nas aulas está presente na realidade econômica da cidade, como conhecimentos químicos são aplicados na indústria, evidenciando a importância da química para a sociedade.

Que este relato atue como incentivo para professores de Química utilizarem cada vez mais recursos tecnológicos durante as aulas, e que os alunos não sejam apenas um expectador, mas produzam, reflitam, argumentem tendo os vídeos e animações como meios para isso.

\section{REFERÊNCIAS}

ARROIO, A., \& GIORDAN, M. O vídeo Educativo: Aspectos da Organização do Ensino, Química Nova na Escola. n. 24, p. 8 - 11, 2006.

BIZELLI, M., FISCARELLI, S., OLIVEIRA, L. Conteúdos Digitais para o Ensino de Cálculo: Aceitação, Demandas e Expectativas dos Alunos. In: IX ENCONTRO IBEROAMERICANDO DE EDUCAÇÃO, 4, 2009. Araraquara: Unesp. Anais do IV EIDE. Araraquara, 2009.

FERRÉS, J. Vídeo e Educação. 2. ed. Trad. J. A. Llorens. Porto Alegre: Artes Médicas, 1996.

FREIRE, P. Pedagogia do Oprimido. 17.ed. Rio de Janeiro: Paz e Terra, 1987

GIORDAN, M. O papel da experimentação no ensino de ciências. Química Nova na Escola. São Paulo, n. 10, p.43-49, 1999.

SILVA, J.L.; SILVA, D.A.; MARTINI, C.; DOMINGOS, D.C.A.; LEAL, P.G.; BENEDETTI FILHO, E.; FIORUCCI, A.R. (2012) A Utilização de Vídeos Didáticos nas Aulas de Química do Ensino Médio para Abordagem Histórica e Contextualizada do Tema Vidros. Química Nova na Escola, v. 34 (04), p. 189 - 200. 